\title{
Percepções de Adolescentes em Período de Internação
}

\author{
Wanderlúcia Flávia Marques ${ }^{1}$, Nadja Maria dos Santos $^{2}$, \\ Flávia Emília Cavalcante Valença Fernandes ${ }^{3}$, Rosana Alves de Melo ${ }^{4}$
}

\begin{abstract}
Resumo: Conhecer as percepções de vida de adolescentes em período de reclusão internos em uma Fundação de Atendimento Socioeducativo. Metodologia: Estudo descritivo, de abordagem qualitativa, realizada com dez adolescentes em período de reclusão na Fundação de Atendimento Socioeducativo, sendo a coleta de dados realizada no período de fevereiro de 2015, através de entrevista semiestruturada. Os dados foram analisados pelo método de análise de conteúdo temática. Resultados: Diversas consequências foram relatadas após o período de reclusão, sendo a principal delas o reconhecimento da importância da família na vida dos adolescentes Conclusão: A mudança de comportamento para com os familiares e a possibilidade de ressocialização são situações possíveis e desejadas por muitos adolescentes que se encontram reclusos, sendo importante repensar uma forma de favorecer o contexto vivenciado por eles durante esse período de internação, com a prática de medidas socioeducativas integralizadas e efetivas.
\end{abstract}

Palavras chaves: Adolescentes; Percepções; Período de internação; Violência; Ressocialização.

\section{Perceptions of Teenagers in Hospitalization Period}

\begin{abstract}
Knowing the teens perceptions of life in times of internal seclusion in a Socio-Educational Services Foundation. Methodology: descriptive study of qualitative approach, carried out with ten teenagers incarcerated in the Socio-Educational Services Foundation, and the collection of data held in February 2015 period, through semi-structured interviews. The data were analyzed using content analysis method. Results: Several consequences have been reported following thedetention period, the main one being the recognition of the importance of family in the lives of teenagers Conclusion: The change of behavior towards the family andthe possibility of social rehabilitation are possible situations and desired by many teenagers who are reclusive, it is important to rethink a way to encourage thecontext experienced by them during the period of hospitalization, with the practice of educational measures paid and effective.
\end{abstract}

Keywords: Adolescents; perceptions; hospitalization; Violence; Resocialization.

\section{Introdução}

Atualmente, a prevalência de atos violentos cometidos por adolescentes com intenção de autoafirmação e outros motivos, tem crescido em todos os contextos sociais, envolvendo uma relação de poder e força, tendo o potencial de causar danos psicológicos, físicos e morais irreversíveis na vida dos indivíduos, e ocorre através de atos infracionais que, segundo o Estatuto da Criança e do adolescente (ECA) (BRASIL, 1990), configura-se em uma conduta descrita como crime ou contravenção penal, passível de internação.

\footnotetext{
${ }^{1}$ Enfermeira. Universidade de Pernambuco. wanderlucia@ hotmail.com. Petrolina, Pernambuco, Brasil;

${ }^{2}$ Enfermeira. Mestre em Educação. Universidade de Pernambuco. nadja.santos@ upe.br. Petrolina, Pernambuco, Brasil;

${ }^{3}$ Enfermeira. Doutoranda em Inovações Terapêuticas. Universidade de Pernambuco. flavia.fernandes@upe.br. Pernambuco, Brasil;

${ }^{4}$ Rosana Alves de Melo*. Enfermeira. Doutoranda em Inovações Terapêuticas. Universidade de Pernambuco. rosana.melo@upe.br. Petrolina, Pernambuco, Brasil; *Autor Correspondente: Rodovia BR 203, Km 2, s/n - Vila Eduardo, Petrolina - PE, 56328-903. Fone: (87) 3866-6470. E-mail: rosana.melo@upe.br
} 
O ECA reconhece como adolescente os indivíduos com idade entre 12 e 18 anos, sendo considerado o período pós infância. A adolescência compreende a fase da vida de maior exacerbação de comportamentos que podem, de alguma forma, afetar a saúde física e mental desse grupo populacional, e consiste em um processo biológico, onde ocorre um rápido desenvolvimento cognitivo e estruturação da personalidade (BRASIL, 1990; SILVA, 2014).

As causas externas são os agravos que tem maior impacto na morbimortalidade de adolescentes, sendo a violência mais frequente, a partir dos 15 anos. Associadas a esses agravos, o porte de arma de fogo e a participação em brigas apresentam uma alta prevalência entre jovens, acarreando altos índices de homicídio e suicídio (SILVA, 2009; ANDRADE et al., 2012).

Considerando o índice de criminalidade entre os adolescentes, existem as instituições de cunho socioeducativo que tem como finalidade, por meio da privação de liberdade ou não, ressocializar os adolescentes que encontram-se em conflitos com a lei. A última medida hierárquica é a internação, que é aplicada pelo juiz, aos adolescentes que cometem atos infracionais de cunho grave, podendo serem reincidentes ou não (AMARAL; SANTOS; OLIVEIRA; PARRÃO, 2014).

A Fundação de Atendimento Socioeducativo (FUNASE) é o órgão responsável pelo atendimento dos adolescentes que estão sob medida socioeducativa de restrição e/ou privação de liberdade, visando a garantia dos seus direitos fundamentais, através de ações conjuntas com outras instituições públicas e a sociedade civil organizada, preconizado pelo ECA, com base Lei No 8.069, de 13 de julho de 1990 (FUNASE, 2015).

As discussões sobre as dificuldades das práticas educativas, no sentido de avaliar se estas favorecem ou desfavorecem a ressocialização, estão cada vez mais fazendo parte das discussões que envolvem a questão da internação de adolescentes. Ressalta-se que, com o aumento exacerbado da violência, os estabelecimentos passam por uma superlotação, favorecendo aumento da periculosidade dos adolescentes, que tem como consequência o aumento da reincidência desses indivíduos.

Considerando as percepções e os sentimentos dos adolescentes que se encontram em período de internação nas instituições de cunho socioeducativo, bem os fatores que envolvem as modificações sociais em suas vidas após esse período, este estudo objetivou Conhecer as 
Id on Line Revista Multidisciplinar e de Psicoloqia

Id on Line Multidisciplinary Journal and Psycology

percepções de vida de adolescentes em período de reclusão internos em uma Fundação de Atendimento Socioeducativo.

\section{Metodologia}

Trata-se de uma pesquisa qualitativa, que segundo Minayo (2012), é um tipo abordagem que tem a capacidade de interligar os significados e a intencionalidade às relações humanas, levando em consideração principalmente os significados e a percepção dos indivíduos.

A pesquisa foi desenvolvida na FUNASE da cidade de Petrolina/PE. A instituição tem como finalidades: planejar e executar as medidas socioeducativas; atender de forma integral os adolescentes; fortalecer o núcleo familiar nas suas funções de sobrevivência, de provisão de afeto e de cidadania, com vistas à convivência familiar e comunitária da criança e do adolescente atendidos lá; dentre outros (FUNASE, 2015).

A amostra foi constituída de adolescentes que estavam em período de internação na referida instituição. Os critérios de inclusão foram estarem internos na Fundação no momento da pesquisa e aceitarem participar desta através da assinatura do Termo de Assentimento Livre e Esclarecido, após a prévia autorização dos pais ou responsáveis, que assinaram o Termo de Consentimento Livre e Esclarecido. Os participantes da pesquisa foram nomeados com a abreviação da palavra "adolescente" e enumerados de acordo com ordem das entrevistas.

A coleta de dados foi realizada em março de 2015, através de uma entrevista semiestruturada, que é aquela que parte de questionamentos básicos, apoiados em teorias e hipóteses e que oferecem amplo campo de interrogativas à medida que se recebem as respostas do informante (MINAYO, 2012).

A entrevista foi composta de quatro questões norteadoras: 1.0 que percebe como ato violento; 2. Principais consequências percebidas em período de internação; 3. Percepção sobre as medidas socioeducativas instituídas pela FUNASE, na intenção de ressocializar; $e 4$. Pretensões após o período de internação. 
As entrevistas foram registradas com auxílio de um gravador portátil, após a autorização do indivíduo, em local e horário preestabelecido, garantindo o sigilo, o anonimato e privacidade.

A análise dos dados foi feita através da técnica de análise de conteúdo temática, após a transcrição das entrevistas e leitura exaustiva das mesmas, posteriormente foi feita a escolha das categorias e discussão dos resultados. A pesquisa foi baseada no que dispõe a Resolução $n$ 466 de 12 de dezembro de 2012, do Conselho Nacional de Saúde (BRASIL, 2012), e também aprovada pelo Comitê de Ética e Pesquisa (CEP), com número de parecer número: 858.196, respeitando todos os preceitos éticos e a autonomia dos indivíduos.

\section{Resultados e Discussão}

Inicialmente foi traçado o perfil sociodemográfico dos entrevistados, dados importantes para conhecer os aspectos que pudessem estar associados ao conteúdo das entrevistas realizadas.

Com relação ao município de procedência dos entrevistados, observou-se que apenas três são de Petrolina/PE, onde está localizada a FUNASE e seis são de cidades circunvizinhas do próprio Estado e também da Bahia. Ressalta-se que a Fundação está organizada para atender adolescentes tanto do município onde está localizada, como dos demais municípios da região circunvizinha, no estado de Pernambuco e Bahia, onde não possua uma instituição com o mesmo perfil assistencial.

No momento da coleta de dados, os motivos pelos quais os adolescentes entrevistados encontravam-se em período de internação variaram entre briga; homicídio; tentativa de homicídio duplamente qualificado; roubo; latrocínio; tráfico de drogas e fuga; sendo que este último demonstra que há adolescentes reincidentes, tanto da referida instituição, como de outros serviços que assistem adolescentes infratores. De acordo com a estatística da FUNASE, do mês de fevereiro de 2015, o tipo de infração mais frequente entre os adolescentes foi roubo/assalto (40,9\%), seguido por tráfico de entorpecentes $(18,3 \%)$, outros $(14,4 \%)$, homicídio $(13,9 \%)$, tentativa de homicídio $(6,2 \%)$, furto $(2,4 \%)$ e latrocínio $(2,3 \%)$ (FUNASE, 2015). 
Com relação ao tempo de internação, observou-se que dos adolescentes entrevistados, nenhum deles tinha mais que 12 meses de internação, sendo que o período que mais prevaleceu foi de quatro a seis meses, dado esse que mostra que o período de internação para esses adolescentes é recente, sendo alguns deles reincidentes.

A faixa etária dos dez adolescentes entrevistados variou entre 14 e 19 anos de idade. Segundo Silva et al., (2009), o grupo de indivíduos entre 10 e 24 anos é considerado o segmento populacional em que as causas externas adquirem sua máxima expressão, considerando que nessa fase os indivíduos estão entre a real perpetuação da fase adulta, com descobertas de papéis nos diversos setores da vida, e a reafirmação, de fato, do momento de escolhas consistentes e incorporação do papel de protagonista de suas próprias escolhas.

Com relação a religião, observou-se que três referem não ter religião definida, três são evangélicos, e quatro deles são católicos. Acredita-se que a prática religiosa influencia de maneira positiva na conduta dos indivíduos, favorecendo o sucesso do processo de ressocialização, pois, segundo Tomé (2011), tem influência benéfica nas atitudes dos frente aos problemas surgidos durante o período de reclusão, além de que, ao expressar sua religiosidade, o homem passa por uma transformação que favorece a sua recuperação e resulta no processo de resiliência.

De acordo com o contexto familiar dos adolescentes entrevistados, apenas um vive em família monoparental, onde há a figura de somente um dos genitores, sendo, a mãe a chefe do núcleo familiar. Nove dos adolescentes entrevistados tem família clássica ou nuclear e possuem irmãos, e apenas um deles referiu ser filho único. Observou-se que os mesmos não possuem maiores problemas familiares, e nesse sentido, Nardi e Anglio (2012) acrescentam que as famílias com problemas estruturais e psicossociais, frequentemente, são menos felizes e apresentam relações hierárquicas não balanceadas.

Com relação ao grau de escolaridade dos entrevistados, dois deles haviam cursado do primeiro ao quinto ano do ensino fundamental; seis cursaram do sexto ao nono ano; um cursou o segundo ano do ensino médio; e um deles até o terceiro ano do ensino médio. Segundo Silva et al. (2009), ao analisar os dados da Pesquisa Nacional por Amostra de Domicílios (PNAD) de anos recentes, expôs que 16\% dos estudantes de escolas públicas que terminam o ensino obrigatório não chegam a se matricular no ensino médio, e dos que se 
matriculam, 18\% não conseguem concluir, o que pode favorecer a maior disponibilidade de tempo dos adolescentes para se envolverem com condutas desviadas.

\section{Percepção sobre ato violento}

De acordo com as experiências vivenciadas pelos adolescentes até o momento, relacionadas a prática de algum tipo de infração, observou-se que os mesmos tem formas bem peculiares de perceberem a ocorrência de ato violento, onde os significados vão desde a prática de assaltar, até mesmo a um espancamento.

\{Ato violento\} É quando você assalta ou bate nas pessoas (Ad. 03). \{Ato violento\} É quando sai sangue (Ad. 04). Violência na minha opinião é espancar os outros (Ad. 07).

Dependendo do contexto sociocultural em que se vive, a prática de ato violento pode ser considerada uma simples conduta, ou mesmo uma forma repugnante de violência em sociedade. Dessa forma, observou-se nas falas dos entrevistados que a definições trazidas, mesmo procedentes de discursos diferentes, se correlacionam entre si, mesmo considerando que cada indivíduo a percebe de uma forma diferente.

Nesse sentido, as percepções trazidas corroboram com o conceito de Andrade et al., (2012), quando afirmam que a violência envolve o uso intencional da força física ou do poder, de modo real ou em ameaça, autoinfligida, interpessoal ou coletiva, que resulte ou tenha alta probabilidade de resultar em lesão, óbito, dano psicológico, deficiência de desenvolvimento ou privação.

Sabe-se que situações consideradas difíceis, são encaradas de forma diferentes pelos indivíduos, levando alguns dos indivíduos a tomarem decisões por impulso. Nesse sentido, a fala de um dos entrevistados mostra que, mesmo entendendo que o ato infracional cometido pode ser por pura defesa, reconhece o mesmo como um ato impensado. 
Para Silva (2014), a juventude é configurada como categoria social, e pode ser entendida como uma representação construída pelos grupos sociais para simbolizar comportamentos e atitudes a ela atribuídos. É a fase de vida onde existe maior expectativa social, associando desenvolvimento de construção social com as transformações biológicas.

Ainda com relação à percepção sobre o ato violento, observou-se nas falas dos entrevistados que alguns o consideram uma prática "normal", e outros são indiferentes à sua propagação no meio social.

A violência pra mim? Sei dizer não \{Face de indiferença\} (Ad. 06) Normal \{Tranquilidade\} (Ad. 10)

A diferença de compreensão por parte dos adolescentes relaciona-se à forma peculiar que cada tem de vivenciar as mesmas situações. Nesse sentido, Nesello et al., (2014) expõem que a violência é inerente à existência humana e manifesta-se de modo peculiar, em espaços sociais distintos, demonstrando que para algumas pessoas há uma ligação de modo íntimo e necessário entre a violência e a natureza destas, e por considerarem ser parte de sua essência, onde em diversas situações a encaram com normalidade.

\section{Percepção de família após o período de internação}

Independente do contexto de vida de cada indivíduo, o núcleo familiar é considerado um espaço de proteção, acolhimento e refúgio diante das diversas situações vivenciadas. Partindo desse entendimento, e de acordo com as falas trazidas, observou-se que o período de internação pode trazer consequências significativas para o contexto familiar do adolesecnte.

Me distanciei da minha família \{tristeza\} (Ad.01); Sinto falta dos meus irmãos. É o que eu mais sinto falta aqui (Ad. O2)

Segundo Nardi e Anglio (2012), a família pode ser considerada como a porta de entrada para o bom convívio social, ao passo que também pode favorecer comportamentos desviados, dependendo da imposição de limites ou não. Esse contexto de desestruturação familiar favorece a perda da capacidade de proteção, suporte afetivo e regulação social das 
relações familiares desses adolescentes. Sendo assim, para que haja o desenvolvimento considerado saudável do adolescente, é necessário que o núcleo familiar incorpore condutas coerentes entre seus membros, com autoridade e respeito.

$\mathrm{Na}$ fala de um dos entrevistados, evidenciou-se maior valorização do núcleo familiar após o período de internação:

Antes era difícil demais, mas quando eu cheguei aqui eu aprendi a valorizar mais minha família \{após o período de reclusão\} [...] (Ad. 04)

Essa percepção do adolescente demonstra que existia uma certa dificuldade de comunicação entre os membros que compõe o seu núcleo familiar, e através do seu relato, percebe-se a vontade de que, a partir de agora, exista uma maior aproximação e diálogo entre eles.

Outra observação feita, diante das falas trazidas, é que existia uma falta de respeito dele para com outros membros da família, principalmente a mãe, o que configurava a falta de empatia entre os mesmos, e após o período de internação, apresentam-se mais sensíveis ao convívio com esses membros.

A falta de respeito com a minha mãe \{antes da internação\}, acho que o modo como eu agia dentro de casa também isso já mudou depois que tô aqui (Ad. 08); Meu modo de ser \{antes da reclusão\} era difícil. Meu respeito sinto que já mudou. (Ad. 05); Uma coisa muito triste era minha família, eu não tinha aquele amor com eles \{antes da reclusão\} (Ad. 03).

Percebe-se que, mesmo o período de internação tendo diversas repercussões negativas nas vidas dos indivíduos internos, nessas situações, em especial, houve a reflexão a respeito dos seus comportamentos diante dos familiares do seu convívio, incluindo pais e irmãos. Dessa forma, ao se pensar no contexto da violência e do período de internação, é necessário levar em consideração que esse ciclo pode ser desconstruído, diante de condutas socializadoras, em prol do bem-estar de cada membro da família e do adolescente, visando uma relação familiar saudável e prazerosa (COSTA, 2012). 
Id on Line Revista Multidisciplinar e de Psicoloqia

Id on Line Multidisciplinary Journal and Psycology

\section{Internação: ressocializar ou dessocializar?}

O período de internação tem diversas conotações que podem ser encaradas como favoráveis ou desfavoráveis, dependendo do ponto de vista e das condições existentes nas instituições que prestam esse tipo de serviço. Diante disso, levanta-se diversos questionamentos, considerando que há, em muitos casos, estrutura física deficiente, poucas verbas financeiras e até mesmo falta de competência e profissionalismo dos profissionais que prestam serviços nessas instituições, e o modo como estes conduzem os adolescentes em período de internação.

Reconhece-se que todas essas situações trazidas, isoladas ou em conjunto, podem desfavorecer o processo de ressocialização, resultando em dessocialização, que segundo Geiger (2015), é considerado o ato de deixar de socializar ou desadaptar à vida social.

De acordo com a fala a seguir, percebe-se que algumas condutas profissionais são vistas pelos adolescentes como algo que pode atrapalhar o processo de ressocialização, ao passo que são encaradas como condutas exclusas e preconceituosas.

Eles \{os profissionais\} não são das pessoas, são muito preconceituosos[...]. Uma pessoa que uma hora ri e outra hora fecha a cara, que não lhe defende. São pessoas que não lhe ajudam nesse sentido (Ad.5); Sinto que as vezes eles \{os profissionais\} excluem a gente, olham estranho, como se não fôssemos nada (Ad. 06).

Estevam, Coutinho e Araújo (2009) ressaltam que na prática, os atendimentos dos programas pedagógicos desenvolvidos em instituições responsáveis pelas práticas socioeducativas vem gerando situações de autodefesa e desagregação social, minimizando o real objetivo de ressocializar. Assim, oportunizar a intensificação da convivência coletiva, com trocas de experiência, podem favorecer a não ocorrência de rebeliões, fugas, mortes e reincidências aos delitos cometidos.

Já de acordo com o ECA (BRASIL, 1990) as medidas socioeducativas estabelecidas para os adolescentes em conflito com a lei variam da advertência à internação, e são levados em conta a gravidade do ato infracional cometido e as condições dos jovens em cumpri-las. Deixa explícito também que o regime de internação ou meio fechado deve ser de um período máximo de três anos.

Ainda de acordo com a publicação supracitada, as medidas socioeducativas aplicadas em regime aberto ou fechado tem a função de incluir esses jovens novamente na sociedade, 
com a possibilidade de oportunizar a reflexão sobre o ato infracional cometido e suas implicações, bem como sobre a reinclusão social, sem que sejam vistos de forma preconceituosa.

Com relação a esse processo de ressocialização, a maioria deles referiu que a vivência na FUNASE é favorável a esse processo, baseado nas medidas socioeducativas aplicadas.

\begin{abstract}
Funciona sim! Porque eles ajudam, trabalham aqui pra valorizar a gente [...] percebem que a gente pode mudar, acolhe bem acolhido, tratam a gente bem[...]. Aí chega uma professora e conversa com a gente, dá uma palavra de conforto pro cara e aí ele pensa duas vezes antes de fazer alguma coisa (Ad.4); Com certeza, ajuda sim a incluir na sociedade. E é uma forma também de mostrar que não é porque a gente tá aqui que a gente tem que ser excluído (Ad.8); Funciona[...]. Lá de onde eu vim o cara não tinha a chance de fazer isso. Não ligava pra estudar, aqui dá tempo de estudar, aprender mais (Ad.9).
\end{abstract}

Os agentes envolvidos na operacionalização das medidas socioeducativas tem a importante missão de proteger, garantir os direitos e educar, dando oportunidades de inserção do jovem na sociedade e o estímulo ao protagonismo juvenil, no que diz respeito à necessidade de participar nas decisões que são do seu interesse e respeitando sua autonomia (ESTEVAM; COUTINHO; ARAÚJO, 2009).

\title{
4. Pretensões após a internação
}

Sabe-se que os diversos contextos de vida influenciam na forma como é percebido as situações vivenciadas. Assim, pode-se assumir posturas que se contrapõem às regras sociais, como também pode-se passar a ter atitudes mais socializadoras, evitando a reincidência de práticas desviadas e dessa forma favorecer o processo de resiliência. De acordo com o Ministério da Saúde (BRASIL, 2010), esse processo de resiliência é compreendido como a capacidade de superar adversidades e de lidar positivamente com situações difíceis, como ficar reclusos por um período de tempo, o que pode causar certo grau de sofrimento.

Quando indagados sobre as pretensões futuras após o período de internação, a maioria dos adolescentes entrevistados expôs a vontade de trabalhar, estudar e se profissionalizar, visando uma mudança no seu contexto de vida. 
Quero trabalhar. Vou até mudar de cidade, pois eu não vou ficar mais lá \{na cidade de origem . (Ad.1); Pretendo trabalhar, me profissionalizar no curso de cabelereiro [...] (Ad.5); Trabalhar bem muito. Estudar, né?! Me formar. Se eu não tivesse feito o que eu fiz eu já estava terminando minha faculdade[...] (Ad.7).

O modo como as medidas socioeducativas são estabelecidas para os adolescentes em período de internação são importantes para delimitar a percepção destes, como algo negativo ou positivo, e potencializar a mudança de seu contexto de vida, futuramente.

$\mathrm{O}$ atendimento, baseado naquilo que é preconizado pelo ECA, pode permitir uma intervenção que garanta o desenvolvimento de programas pedagógicos, atividades escolares, profissionalização, esporte, artes e de atividades de saúde, proporcionados de maneira sistemática (ESTEVAM; COUTINHO; ARAÚJO, 2009; BRASIL, 2010). Tudo isso poderá resultar na reflexão do adolescente sobre o seu contexto de vida atual, para que este busque novos direcionamentos e favoreça o seu retorno ao seu convívio social e familiar.

\section{Conclusão}

A ocorrência de atos violentos é uma problemática bastante presente na nossa realidade e tem o potencial de afetar substancialmente a vida de todos os envolvidos. Os adolescentes aparecem nesseS contextos, muitas vezes como propagadores desses atos violentos, sendo necessário ficarem um tempo pré-determinado sob internação, no intuito de evitar que cometam mais delitos e seja favorecida sua ressocialização.

Observou-se nesse estudo que a percepção dos adolescentes acerca dos atos infracionais cometidos e suas implicações na sociedade e em suas próprias vidas, é um fenômeno complexo, já que sua compreensão, ora converge, ora diverge daquilo que é estabelecido com norma social, no sentido de que em algum momento eles visualizam essa infração de conduta como algo banal.

Percebeu-se que a principal consequência, após ficarem reclusos, foi a mudança de comportamento a respeito de suas famílias, demonstrando uma maior valorização das pessoas desse ciclo, sendo evidenciado pela distância da família na vida dos adolescentes a falta que o núcleo familiar faz, tendo sido referenciado por eles. 
Apesar de alguns entrevistados não acreditarem na possibilidade de serem ressocializados, os resultados mostraram que eles confiam no trabalho proposto pela Fundação, assim como o trabalho dos agentes de operacionalização das ações socioeducativas, como possibilidade de reinserção social. Nesse sentido, as principais pretensões deles, após o término do período de internação, envolvem estudar e trabalhar, visando uma mudança de vida futura.

Dessa forma, entende-se que o presente estudo é relevante, pois além de haver poucas pesquisas com essa abordagem, permite uma visão mais integral sobre os adolescentes em período de internação, permitindo que se conheça suas compreensões e percepções, de forma a direcionar as abordagens sociais voltadas a esses grupos. O estudo apresentou como principal limitação a dificuldade de acesso das pesquisadoras a Fundação, o que tardou um pouco mais a construção dos resultados.

\section{Agradecimentos}

À FUNASE que, apesar da resistência inicial, nos permitiu o acesso às suas dependências; e nossa gratidão a cada adolescente entrevistado, por nos conceder a honra de conhecer um pouco do seus mundos, suas percepções de vida e seus anseios futuros.

\section{Referências}

AMARAL, A. C., ET AL. O adolescente em cumprimento de medidas socioeducativas de liberdade assistida e prestação de serviços à comunidade no centro de referência especializado de assistência social. ETIC 2014 - Encontro de Iniciação Científica ISSN 21-76-8498.

ANDRADE, S. ET AL. Relação entre violência física, consumo de álcool e outras drogas e bullying entre adolescentes escolares brasileiros; Cad. Saúde Pública, Rio de Janeiro, 28(9): 17-25-1736, set, 2012.

BRASIL. Estatuto da Criança e do Adolescente. São Paulo: Cortez, 1990. 181p.

BRASIL. Ministério da Saúde. Secretaria de Atenção à Saúde. Área de saúde do adolescente e do jovem. Marco legal: saúde, um direito do adolescente. Brasília: MS, 2007. 
Id on Line Revista Multidisciplinar e de Psicologia

Id on Line Multidisciplinary Journal and Psycology

BRASIL. Ministério da Saúde. Linha de cuidado para a atenção integral a saúde da criança, adolescentes e suas famílias em situação de violência: orientação para gestores e profissionais de saúde. Brasília: MS, 2010.

BRASIL. Ministério da Saúde. Resolução 466/12. Diretrizes e normas regulamentadoras de pesquisas envolvendo seres humanos. Conselho Nacional de Saúde. Brasília, DF: MS, 2012

COSTA, A.P.M. Adolescência brasileira e o contexto de vulnerabilidade à violação de direitos fundamentais. Rev. Brasileira de Direito, IMED, Vol. 8, n 2, jul-dez 2012.

ESTEVAMO, I., COUTINHO, M., ARAÚJO, L. Os desafios da prática socioeducativa de privação de liberdade em adolescentes em conflito com a lei: Ressocialização ou exclusão social? PSICO, Porto Alegre, PUCRS, v. 40, n. 1, PP; 64-72, jan./mar. 2009.

FUNASE - Fundação de Atendimento Socioeducativo: Finalidade, visão e valores e estatística. Disponível em: <http://www.funase.pe.gov.br/missao_visao_valores.php> Acesso em: 01 jun. 2015

GEIGER, P. Aulete Digital. 2015. Disponível em: < http://www.aulete.com.br/dessocializa\%C3\%A7\%C3\%A3o > Acesso em: 09 jun. 2015.

NARDI, F., ANGLIO, D. Adolescentes em Conflito com a Lei: Percepções sobre a Família; Psic.: Teor. e Pesq., Brasília, Abr-Jun 2012, Vol. 28 n.2, pp. 181-191.

NESELLO, F., et al. Características da violência escolar no Brasil: revisão sistemática de estudos quantitativos; Rev. Bras. Saúde Matern. Infant., Recife, 14 (2): 119-136 abr. / jun., 2014.

SILVA, R., et al. Prevalência e fatores associados a porte de arma e envolvimento em agressão física entre adolescentes de 15 a 18 anos: estudo de base populacional; Cad. Saúde Pública, Rio de Janeiro, 25(12):2737-2745, dez, 2009.

SILVA, J. G. Homicídios de jovens no Brasil: o desafio de compreender a consequência fatal da violência. Rio de Janeiro, 2014. Tese apresentada com vistas à obtenção do título de Doutor em Ciências na área de Saúde Pública, Universidade Estadual do Rio de Janeiro/RJ.

\section{Como citar este artigo (Formato ABNT):}

MARQUES, W.F.; SANTOS, N.M.; FERNANDES, F.E.C.V.; MELO, R.A. Percepções de adolescentes em período de internação. Id on Line Revista Multidisciplinar e de Psicologia, Out-Nov. de 2016, vol.10, n.31, Supl 3, p. 08-20. ISSN 1981-1179.

Recebido: 24/10/2016

Aceito: 25/10/2016 